\title{
A DEMOCRATIZAÇÃO DO LUXO E O CONSUMO DE SENSAÇÕES: PODER SIMBÓLICO E REDES SOCIAIS EM RELAÇÃO AO DESENVOLVIMENTO SOCIAL HUMANO
}

\section{Alessandra Brustolin* Cátia Rejane Mainardi Lickzsbinsk ${ }^{* *}$}

\section{RESUMO}

O artigo pretende realizar uma análise crítica em relação a atual fase da sociedade de consumo impulsionada pelo processo de globalização, principalmente após a "democratização do luxo". Os objetos e pessoas são elementos de distinção social e símbolo de pertencimento a grupos sociais. Com o passar dos anos o consumo passou a ser protagonista e ditar as regras sociais, a aquisição tornou-se um ato de satisfação pessoal que invade o campo dos sentidos. $\mathrm{O}$ que se busca questionar é a necessidade de consumir para ser visto e como isso afeta o desenvolvimento social humano. O método utilizado será o dedutivo.

Palavras-Chave: Globalização. Luxo. Consumo. Redes Sociais. Desenvolvimento Social Humano.

\section{THE DEMOCRATIZATION OF LUXURY AND THE CONSUMPTION OF SENSE: SYMBOLIC POWER AND SOCIAL NETWORKS IN RELATION TO HUMAN SOCIAL DEVELOPMENT}

\begin{abstract}
The article intends to carry out a critical analysis in relation to the current phase of consumer society driven by the globalization process, especially after the "democratization of luxury". The objects and people are elements of social distinction and symbol of belonging to social groups. Over the years, consumption became a protagonist and dictates social rules, acquisition became an act of personal satisfaction that invades the field of the senses. What is sought to question is the need to consume to be seen and how it affects human social development. The method used will be the deductive.
\end{abstract}

Keywords: Globalization. Lux. Consumption. Social networks. Human Social Development.

\section{INTRODUÇÃO}

O processo de uma globalização muito mais rápida e fluida da vida social nos últimos anos, que conecta as sociedades nos mais diversos âmbitos, trouxe sérias implicações na vida do ser humano. Dentre elas, a aceleração das mudanças sociais que, analisada sob a ótica da volatilidade e temporalidade, acabou por cultivar as sementes de um novo prefixo, o

\footnotetext{
*Advogada. Especialista. Pós-Graduanda em Direito Processual Civil pela UNIPAR - Universidade Paranaense. Endereço postal: Rua Paraná, 3262 - 2º Andar, Centro, Cascavel - PR, 85810-010. Endereço eletrônico: alessandrabr.adv@outlook.com

** Doutora em Direito. Mestre. Especialista. Professora na FURB - Universidade Regional de Blumenau - SC. Endereço Postal: rua Desembargador Pedro Silva, 154, Blumenau - SC, 89012-150. Endereço Eletrônico: catia_sarreta@hotmail.com
} 
"hiper". Evidencia-se, pois, em lugar da pós-modernidade, a hipermodernidade, que acabou inundando o campo social e humano.

A rápida transformação da sociedade de produtores em sociedade de consumo também fez com se chegasse ao modelo atual denominado sociedade de hiperconsumo. A diferença entre esses estágios é tão somente de ênfase e prioridades, porém, estabelece uma larga e vertiginosa mudança na vida individual e em quase todos os aspectos da sociedade, o que atinge diretamente as noções de desenvolvimento social humano.

Na sociedade de hiperconsumo o consumidor passou a centro e a ditar as regras de consumo. Com isso, criou-se uma ilusão de que é ele o detentor de plena liberdade de escolha, quando na verdade, não se tem opção. O luxo passa a ser utilizado como forma de demarcar identidade, que confere um status social diferenciado, não tanto com a avidez de possuir, com relação ao acúmulo de riqueza no sentido material, mas no campo das experiências e sensações que ele pode propiciar.

As práticas cotidianas de consumo na hipermodernidade, atreladas ao fenômeno de influência das redes sociais atinge todos os setores da sociedade, na medida em que interfere nas relações interpessoais, fortalece a exclusão e o individualismo, refletindo uma sociedade pulverizada de indivíduos solitários e famílias fragmentadas, o que atinge diretamente o processo de desenvolvimento social humano.

Tendo em vista a lacuna existente em estudos anteriores realizados, com vistas a relacionar esse fenômeno ao desenvolvimento social humano, a presente pesquisa busca problematizar os padrões impostos pela sociedade de hiperconsumo, sobretudo na atual conjectura de exposição através das redes sociais, por meio dos questionamentos seguintes: Os padrões impostos na atual sociedade de hiperconsumo, especialmente com a ascensão das redes sociais, são capazes de gerar um retrocesso no desenvolvimento social humano? Quais as estratégias podem ser adotadas pelos Estados para superar o simbólico e a ideia de felicidade paradoxal com relação ao consumo, em busca da concretização do desenvolvimento social humano?

Diante dessas problemáticas, são levantadas hipóteses de que os padrões impostos pela sociedade de hiperconsumo obstam o desenvolvimento social humano, pois como impõem a prevalência do individualismo, exclusão social e desigualdade, atingem diretamente os fatores relevantes para a mobilização e crescimento social, que são o cerne de uma sociedade equitativa. No segundo plano, como meio de driblar esse retrocesso, apresenta-se a aplicação de um o processo de desenvolvimento numa abordagem ampla, que associe considerações econômicas, sociais e políticas, bem como promova expansão das liberdades Revista de Direito e Sustentabilidade | e-ISSN: 2525-9687 | Salvador | v. 4 | n. 1 | p. 77 - 94 | Jan/Jun. 2018 


\section{A DEMOCRATIZAÇÃO DO LUXO E O CONSUMO DE SENSAÇÕES: PODER SIMBÓLICO E REDES SOCIAIS EM RELAÇÃO AO DESENVOLVIMENTO SOCIAL \\ HUMANO}

reais que as pessoas desfrutam em busca de um desenvolvimento social humano de forma sustentável.

Acredita-se na relevância da promoção de discussões onde se coloca em pauta o pensamento acerca de uma sociedade de consumidores (utilizando o viés do consumo de luxo), que se (re)constroe a medida que se propagam (falsas) afirmações diárias pelas redes sociais de que a felicidade pessoal pode e está ligada ao poder de consumo.

Os objetivos da pesquisa consistem em demonstrar a evolução do consumo, partindo da aquisição de objetos como elemento de distinção social e símbolo de pertencimento a grupos sociais, até a aquisição como espécie de satisfação pessoal e merecimento, que invade o campo dos sentidos, principalmente após a "democratização do luxo", identificando os significados de luxo para os brasileiros e elencando as diferenças entre luxo desejado e luxo possível/permitido.

Constatados esses pontos, são trazidas reflexões que relacionam a atual cultura de exposição através das redes sociais como fator propulsor de uma "felicidade paradoxal" e prejudicial à concretização do desenvolvimento social humano. Por fim, busca-se solucionar a problemática central utilizando o método de pesquisa dedutivo, tendo como base as obras de Pierre Bourdieu, Jean Baudrillard, Zigmunt Bauman, Gilles Lipovetsky, dentre outros autores, em busca da concretização do desenvolvimento social humano.

\section{PERCEPÇÃO, REPRESENTAÇÃO E O SIMBÓLICO}

Os valores que definem uma cultura são compostos por percepções e representações que tem uma dada importância, significado e um símbolo. Mas isso encontra dificuldades. Atualmente, o ser humano está colocado neste centro em que a compressão tempo/espaço tem mostrado as várias faces das transformações que estão ocorrendo nas condições humanas.

Onde antes havia concentração de indivíduos, favorecendo a ação política, hoje há dispersão. Os espaços públicos estão cada vez mais sendo substituídos por espaços privados e os que existem tendem a ser cada vez mais elitizados, aumentando o poder dos mais fortes e enfraquecendo os despossuídos. Cada vez mais o ser humano tem sido aviltado em seus direitos, tem sido espoliado de sua condição de liberdade para agir e decidir, mostrando que a globalização não beneficia a todos de maneira uniforme.

Segundo Bauman (1999, p. 8), “A globalização tanto divide como une; divide enquanto une - e as causas da divisão são idênticas às que promovem a uniformidade do globo". Assim, a globalização, neste aspecto de ao mesmo tempo unir ou desunir as pessoas, Revista de Direito e Sustentabilidade | e-ISSN: 2525-9687 | Salvador | v. 4 | n. 1 | p. 77 - 94 | Jan/Jun. 2018 
mostra que diante de situações semelhantes existem atuações, reações participações dos sujeitos sociais de forma diferente.

As representações estão relacionadas a uma aceitação por parte da sociedade de determinados valores sociais que acabam se estabilizando. Essas representações para permanecerem devem estar em constante "lembrança".

Para Bourdieu há um sistema de representação onde estão inteiramente diluídas criando relações de poder. As ações e interações dos grupos sociais no plano simbólico e econômico ocorrem em razão da imposição das regras pelo grupo dominante. As percepções e sensações criadas no interior do simbólico estão relacionadas a um determinado espaço físico. O campo simbólico possui particularidades, adaptando-se aos aspectos locais no qual ele foi criado.

As representações sociais são modalidades de conhecimento prático, orientadas para a comunicação e para a compreensão do contexto social, material e ideativo em que vivemos. São consequentemente, formas de conhecimento que se manifestam como elementos cognitivos - imagens, conceitos, categorias, teorias -, mas que não se reduzem jamais aos componentes cognitivos. Sendo socialmente elaboradas e compartilhadas, contribuem para a construção de uma realidade comum, que possibilita a comunicação.

Deste modo, as representações são, essencialmente, fenômenos sociais que, mesmo acessados a partir de seu conteúdo cognitivo, têm de ser entendidos a partir do seu contexto de produção (JODELET, 1985, p. 469-494). As representações são coletivas, mas vividas, individualmente na compreensão do homem e sua análise dos fatos e da própria sociedade.

O termo "Representações Sociais" é como um conjunto de explicações que se originam por meio das comunicações interindividuais da vida cotidiana. Elas se constituem num trabalho mental do sujeito que tem como resultado a formação de uma imagem do objeto. É um ato do pensamento que traz para perto o que estava longe, que torna familiar o que era estranho (atribuído por Serge Moscovici, psicólogo francês criador da teoria em 1961).

Buscam compreender os fenômenos sociais e a maneira como estes são captados, interpretados, visualizados e expressos no cotidiano pelos indivíduos ou grupos sociais. Nessa perspectiva, as representações sociais possibilitam ao sujeito tomar consciência de seus pensamentos, de suas ideias, de sua visão, de suas atitudes, levando-o a acumular conflitos e a encontrar uma maneira de tornar familiar aquilo que lhe é desconhecido.

De acordo com Moscovici (1978), as representações sociais emanam de situações da sociedade presente, tendo como função contribuir para os processos de formação de condutas Revista de Direito e Sustentabilidade | e-ISSN: 2525-9687 | Salvador | v. 4 | n. 1 | p. 77 - 94 | Jan/Jun. 2018 


\section{A DEMOCRATIZAÇÃO DO LUXO E O CONSUMO DE SENSAÇÕES: PODER SIMBÓLICO E REDES SOCIAIS EM RELAÇÃO AO DESENVOLVIMENTO SOCIAL \\ HUMANO}

e de orientação das comunicações sociais. Assim, segundo esse mesmo autor, as representações sociais equivalem a um conjunto de princípios construídos interativamente e compartilhados por diferentes grupos que através delas compreendem e transformam a realidade (MOSCOVICI, 1978).

A estrutura das representações sociais se configura a partir das seguintes dimensões: 1) Informação - relaciona-se com a organização dos conhecimentos que um grupo possui a respeito de um objeto; 2) Campo de representações - associa-se à imagem do conteúdo concreto do objeto da representação; 3) Atitude - indica a orientação global em relação ao objeto da representação social (MOSCOVICI, 1978).

De acordo com Sales (1999), a representação social de um dado objeto "é resultado da transformação mental de um objeto em figura e da significação que o sujeito atribui a esse objeto. Isto quer dizer que a toda figura está associada uma significação e a toda significação uma figura" (p. 16).

Em relação à perspectiva da cultura do poder político, a representação social de indivíduos ou grupos é necessária para se entender como os atores sociais, estão percebendo a situação. A integração a sociedade pressupõe o conhecimento dos valores essenciais a essa sociedade e que definem as representações. Estar integrado à sociedade pressupõe conhecer os processos e mecanismos de formação dessas representações.

As representações são mutantes e os membros da sociedade estão expostos a uma situação de constante aprendizagem da formação do simbólico, o que significa que não existe uma aquisição definitiva (MCLEÓDE, 1997, p.147-162).

Para o homem participar dos espaços sociais ele precisa aceder aos valores estabelecidos conquistando o seu espaço na sociedade a ainda compreendendo os processos de constituição desses valores e suas representações.

Segundo McLeóde (1997, p. 147-162)

Se os valores que constituem o simbólico repousam sobre representações e se estas representações devem ser constantemente reiteradas, então a dicotomia clássica entre a ordem da significação e a ordem da comunicação desaparece, eis aí, de fato, duas maneiras diferentes de se aprender um mesmo sistema. Ou simplesmente: os processo de comunicação poderiam ser aprendidos como uma divisão desses processo de construção de reiteração e de modificação das representações que formam o simbólico. 
O simbólico ${ }^{1}$ está presente em um conjunto de representações que o homem faz do mundo e de como compreende este mundo. A realidade se apresenta por meio das representações, como exemplo a língua.

O poder simbólico (re)constrói as necessidades sociais, fornecendo uma nova percepção de mundo. Tudo é muito dinâmico e envolvente. As articulações ocorrem por meio de estratégias de dominação estruturadas para essa finalidade e que passam na maioria das situações “despercebidas pelo ator”. Segundo Touraine, este é domínio onde a ruptura entre o sistema e os atores parece ser mais difícil de se conceber (TOURAINE, 1994, p.151-152).

O simbólico é um tipo de poder que se faz reconhecer e obter o reconhecimento. É um poder não perceptível exercido com a cumplicidade tanto daqueles que se submetem, como os que exercem o poder. Os agentes apreendem os objetos ofertados simbolicamente e fornecem sentidos e significados distintos a suas práticas, o que os diferem dos demais e acaba gerando a criação de poderes e hierarquias.

Ao se interrogar sobre os mecanismos e processos de construção do simbólico, se atinge o nível de representação. "Ser interpretado é assegurar a sua entrada no mundo social, no mundo do simbólico. Porque participar da vida social não é possuí-la ou dominar a sociedade. É fazer parte dela, ser um membro desta sociedade.” (MCLEÓDE, 1997, p.147162).

Para os antropólogos, o ambiente em que vivemos é duplo, a um só tempo natural e cultural, sem que talvez se possa afirmar em qual dos domínios as nossas raízes são mais profundas. Nesse contexto, afirma-se que o poder simbólico é uma forma transfigurada e legitimada das outras formas de poder (BOURDIEU 2000).

De acordo com Bourdieu (2000) o simbólico transcende a alternativa dos modelos energéticos que descrevem as relações sociais como relações de força e dos modelos cibernéticos que fazem das relações de comunicação na condição de se descreverem as leis de transformação que regem a transmutação das diferentes espécies de capital simbólico, o que

\footnotetext{
${ }^{1}$ O poder simbólico como poder de constituir o dado pela enunciação, de fazer ver e fazer crer, de confirmar ou de transformar a visão do mundo e, deste modo, a ação sobre o mundo, portanto o mundo poder quase mágico que permite obter o equivalente daquilo que é obtido pela força (física ou econômica graças ao efeito específico de mobilização, só se exerce se for reconhecido, quer dizer, ignorado como arbitrário. Isso significa que o poder não reside nos "sistemas simbólicos" em forma de uma "illuctionary force" mas que se define numa relação determinada - e por meio desta- entre os que exercem o poder e os que lhe são sujeitos, quer dizer, isto é, na própria estrutura doem que se produz e se reproduz a crença. O que faz o poder das palavras e das palavras de ordem, poder de manter a ordem ou de a subverter, é a crença na legitimidade das palavras e daquele que as pronuncia, crença cuja produção não é da competência das palavras (BOURDIEU, 2000, p.14-15).
} 


\section{A DEMOCRATIZAÇÃO DO LUXO E O CONSUMO DE SENSAÇÕES: PODER SIMBÓLICO E REDES SOCIAIS EM RELAÇÃO AO DESENVOLVIMENTO SOCIAL \\ HUMANO}

garante uma verdadeira transubstanciação das relações de força (ignoradas-reconhecidas), transformando-as assim em poder simbólico, capaz de produzir efeitos reais sem dispêndio aparente de energia.

O consumo, tal como é posto atualmente, configura a demonstração do simbólico, essa forma de poder (ignorada-reconhecida) que é diariamente exercida sobre os indivíduos. Não aquele consumo decorrente da conduta natural do ser humano, sem limites temporais ou históricos, mas enquanto representação própria de reconhecimento do indivíduo na sociedade, o que afeta diretamente o desenvolvimento social humano.

\section{GLOBALIZAÇÃO E A "DEMOCRATIZAÇÃO DO LUXO"}

O desenvolvimento global da humanidade, desde o surgimento do planeta terra ${ }^{2}$, ocupou a maior parte da história humana. Em uma comparação da existência humana com um dia de 24 horas, afirma-se que a agricultura teria passado a existir às 23h56min., as civilizações às 23:57 e o desenvolvimento das sociedades modernas começaria apenas às 23:59:30. Assim, os últimos 30 segundos desse dia humano produziriam mudanças sociais e ambientais mais rápidas que todo o tempo que passou antes deles (GIDDENS, 2012).

Essa constatação serve para ilustrar uma globalização muito mais rápida e fluida da vida social nos últimos anos, tendo em vista o rompimento das fronteiras nacionais e a conexão entre sociedades nos mais diversos âmbitos: trocas econômicas, acordos políticos internacionais, turismo global, tecnologia de comunicações, padrões de migração, etc.

O processo de globalização trouxe sérias implicações na vida do ser humano e gerou uma aceleração muito grande das mudanças sociais. Esse fenômeno, analisado sob a ótica da volatilidade e temporalidade, incide diretamente no processo cultural de cada povo e de cada região, já que o rompimento das fronteiras nacionais é o seu cerne. As grandes potências e empresas multinacionais cada dia ganham mais força e domínio sobre os países em desenvolvimento, o que contribui para o agravamento das desigualdades sociais.

Tamanha é a aceleração das mudanças sociais, que se acabou por assentar as bases um novo prefixo, o "hiper" e assim também ocorre com relação ao consumo. Na atual sociedade de hiperconsumo há um deslocamento do significado e das motivações do consumo para o campo dos sentidos, com a valorização das sensações e experiências, sendo o consumo utilizado como sinônimo de merecimento, o que gera uma felicidade paradoxal. Esse

2“O planeta Terra, segundo dizem os geólogos, tem uma idade quase inimaginável de 4 bilhões e meio de anos. Os seres humanos existem na Terra há mens de meio milhão de anos" (GIDDENS, 2012, p. 80). 
fenômeno justifica-se, historicamente, pela melhora das condições de vida e estabilização da economia.

No Brasil, a melhora na estabilidade econômica e política, ocorrida sobretudo a partir dos anos 2000, contribuiu para essas mudanças nos padrões individuais de mobilidade e no próprio sistema de estratificação social. O crescimento da classe média e de seu poder de compra ajudaram na expansão do mercado consumidor, além de fixar os novos padrões e tendências de consumo.

Esses novos padrões e tendências estão voltados à satisfação do prazer e movidos pelo viés do luxo. O mercado do turismo e da alimentação cresceu significativamente, passando a serem estes alguns dos "luxos" que os indivíduos se permitem atualmente. Afirma-se que essas mudanças atreladas à emergência que acompanha a atual sociedade foram cruciais para a chamada "democratização do luxo" (LIPOVETSKY, 2005). No entanto, a sustentação dessa situação apresenta um risco que beira ao fracasso.

No decorrer da história, o luxo foi identificado como símbolo de distinção social e objeto das lutas de classes. Antigamente o luxo era reservado aos círculos da burguesia. Porém, nas últimas décadas o panorama mudou, a visibilidade do luxo cresceu. Não há mais um luxo, mas "luxos" destinados a públicos diversos, em vários graus, o luxo aparece como um bem alcançável de quase todos os bolsos (LIPOVETSKY, 2005). De acordo com Lipovetsky (2005) “A arte de viver que acompanha o luxo não é mais uma convenção de classe, é teatro para melhor provar dos prazeres dos sentidos".

É inegável que o consumo, ou melhor, a forma de consumo, contribuiu para essas modificações sociais. Dada a complexidade da situação, existe uma preocupação não somente pela estabilidade da posição socioeconômica, mas, principalmente, mas com relação ao imperialismo do hiperconsumo, principalmente com relação ao supérfluo, enquanto obstáculo ao desenvolvimento social humano.

Isso porque, mesmo em uma época em que o importante é o presente, o luxo busca a eternidade. Do transitório extrai-se o eterno. O supérfluo tornou-se primordial, o que denota uma inversão de valores, pois o luxo deixa de ser uma forma de distinção de classes para se tornar uma relação emocional e isso afeta significativamente o desenvolvimento social humano.

Nossa época vê manifestar-se o "direito" às coisas supérfluas para todos, o gosto generalizado pelas grandes marcas, o crescimento de consumos ocasionais em frações ampliadas da população, uma relação menos institucionalizada, mais personalizada, mais afetiva com os signos prestigiosos: o novo sistema celebra as bodas do luxo e do individualismo liberal. Mutações que convidam a reconsiderar o 
sentido social e individual dos consumos dispendiosos, bem como o papel tradicionalmente estruturante das estratégias distintivas dos afrontamentos simbólicos entre grupos sociais. É realmente uma nova cultura do luxo que cresce sob nossos olhos. (LIPOVETSKY, 2005 p. 16).

O luxo está em toda parte. Relacionar esse fenômeno ao atual cenário de exposição por meio das redes sociais e compreender essa conexão a partir de um novo significado, demonstra-se um grande desafio. Sobretudo sob a perspectiva vivenciada em tempo de crise e como o desenvolvimento relaciona-se com a melhora da qualidade de vida dos indivíduos e no fortalecimento de suas liberdades.

Diante da lacuna existente em estudos anteriores realizados, convém examinar se os padrões impostos na atual sociedade de hiperconsumo, com a ascensão das redes sociais, são capazes de gerar um retrocesso no desenvolvimento social humano. E quais as estratégias podem ser adotadas pelos Estados para superar o simbólico com relação ao consumo, em busca da concretização do desenvolvimento social humano.

Assim, acredita-se na relevância social e teórica, da promoção de discussões a este respeito, centradas no pensamento acerca de uma sociedade de hiperconsumo pelo viés do luxo, que se (re)constrói à medida em que se propagam (falsas) afirmações diárias de que a felicidade pessoal pode e está ligada ao poder de consumo. Principalmente se ele estiver estampado nas redes sociais, buscando demonstrar como os padrões de consumo atualmente impostos são capazes de gerar um retrocesso no âmbito do desenvolvimento humano e social (ações movidas por racionalidades que atuam no sistema econômico e social), além de trazer estratégias capazes de enfrentar e superar essa situação.

\section{CONSUMO DE SENSAÇÕES E AS REDES SOCIAIS EM RELAÇÃO AO DESENVOLVIMENTO SOCIAL HUMANO}

O luxo invadiu a internet e as redes sociais se tornaram um tipo de capital $^{3}$. Analisando a globalização por essa ótica, a integração entre os indivíduos ajuda na melhora de suas qualificações, promoção de carreira, aumento da produtividade estímulo e cooperação pelas trocas de informações, o que é bastante positivo. Por outro lado, essa relação também fabrica danos colaterais, o que atinge diretamente o processo de desenvolvimento social humano.

\footnotetext{
${ }^{3}$ A palavra "capital", geralmente empregada em relação ao maquinário usado na profissão (físico), aqui deve ser compreendida em sentido amplo, que inclui as qualificações do ser humano.
} 
É inegável que o consumo, ou melhor, a forma de consumo, possui influência na construção dos valores e práticas de uma sociedade e, portanto, traz modificações sociais significativas. As práticas cotidianas de consumo na hipermodernidade, atreladas ao fenômeno de influência das redes sociais atinge todos os setores da sociedade, pois interfere na economia, na política e nas relações interpessoais, refletindo uma sociedade pulverizada de indivíduos solitários e famílias fragmentadas, capazes de gerar um retrocesso no desenvolvimento social humano.

A internet, apesar de suas inegáveis contribuições, apresenta riscos à sociedade e ao ser humano em si. Denota-se que com a utilização das redes sociais, os indivíduos se inclinam para a cultura de exposição em um "Big Brother" da vida real, na busca constante (e urgente) de uma felicidade que necessita ser experimentada, mostrada e isso só é possível por meio do consumo: o consumo das sensações. Que é incrivelmente propiciado pela "democratização do luxo".

Essa nova era anunciada pelo luxo é marcada pela aceleração dos movimentos sociais: difusão de cópias, expansão da falsificação, fusões, aquisições e cessões de marcas em um mercado globalizado, isolamento da população, culto ao individualismo e exclusão das minorias. Tudo isso pode ser sintetizado no definhamento da solidariedade social, que ocorre na medida do desaparecimento do efetivo compartilhamento, quando só se compartilha por meio das redes sociais, a tendência é a do afastamento. De uma sociedade cada vez menos hospitaleira, pois se instala a estabelece e a (auto)exclusão.

Assim, quando as ligações estabelecidas pelas redes sociais mitigam, o desempenho econômico e humano padece. Vale ressaltar que se trata também de um fenômeno histórico, na medida em que a população dos países desenvolvidos tornou-se mais isolada, com senso de comunidade reduzido desde os anos 1960, o que contribuiu para o declínio econômico, na medida em que o capital social é tido em geral como elemento significativo do desempenho econômico, conforme observou Putnam (1996).

Com relação às influências do luxo no desenvolvimento social de campo econômico, o momento atual é marcado "[...] pela aceleração dos movimentos de concentração, pelas fusões, aquisições e cessões de marcas em um mercado globalizado. O momento é o da financeirização do setor, sem que por isso desapareçam os imperativos específicos de criatividade e de excelência dos produtos." (LIPOVETSKY, 2005, p. 14 - 15). Isso agrava a exclusão das minorias.

Com relação às formas de consumo, na atual sociedade de hiperconsumo há um deslocamento do significado e das motivações para o campo dos sentidos, com a valorização das sensações e experiências, sendo o consumo utilizado como sinônimo de merecimento. 


\section{A DEMOCRATIZAÇÃO DO LUXO E O CONSUMO DE SENSAÇÕES: PODER SIMBÓLICO E REDES SOCIAIS EM RELAÇÃO AO DESENVOLVIMENTO SOCIAL \\ HUMANO}

"Por definição, o domínio do luxo é o da excelência e da emoção" (LIPOVETSKY, 2005, p. 99).

Ocorre que a sustentação desse estatuto social do luxo apresenta um risco que beira ao fracasso, pois é inegável que o consumo, ou melhor, a forma de consumo, contribuiu para essas modificações sociais.

\footnotetext{
Em um mundo de rápidas mudanças, as formas tradicionais de confiança se dissolvem. Nossa confiança nas pessoas começava a se basear em comunidades locais, mas, nas sociedades mais globalizadas, nossas vidas são influenciadas por pessoas que jamais conhecemos ou encontramos, que podem viver do outro lado do mundo em relação a nós. Esses relacionamentos interpessoais significam que somos forçados a "confiar" ou ter confiança em "sistemas abstratos" [...]. Dessa forma, a confiança e o risco estão intimamente ligados. A confiança nas autoridades é necessária se quisermos confrontar os riscos que nos rodeiam e reagir a eles de um modo efetivo (GIDDENS, 2012, p. 112).
}

Na sociedade de hiperconsumo "[...] o hedonismo contemporâneo se conjuga com a ansiedade e violência no relacionamento social, dando origem a um verdadeiro punhal de decepção" (LIPOVETSKY, 2007, p. 279). Os fatores que alimentam a torrente consumista são a "[...] a desagregação dos lados sociais, o recuo dos sentimentos de inclusão numa comunidade, o aumento da incerteza, a fragilização da vida profissional e afetiva, o afrouxamento dos laços familiares [...] crises subjetivas e intersubjetivas" (LIPOVETSKY, 2007, p. 291).

As sensações e experiências geradas pelo uso de produtos ou serviços de luxo ou, melhor dizendo, aquelas supostamente imaginadas, passam a ser ditadas por hábitos idealmente adquiridos e por uma cultura que envolve sobretudo o esquecimento, não o aprendizado. $\mathrm{O}$ que realmente conta é a volatilidade, a instigante experiência em viver aquilo que não sabia que existia, de ser atormentado pelos desejos ainda não percebidos e nem suspeitados.

Com relação ao novo padrão de sociedade é salutar destacar a figura das redes sociais como impulsionadora do ritmo das modificações sociais, pois

\footnotetext{
Uma influência cultural particularmente importante que afeta o caráter e o ritmo da mudança é a natureza dos sistemas de comunicação. [...] Com o advento da internet, a comunicação também se tornou muito mais rápida e distância um obstáculo muito menor. Ela também gerou um senso mais efetivo de sociedade global do que havia antes (GIDDENS, 2012, p. 99).
}

Por mais que pareça redundante, a realidade é que os usuários (literalmente) ficam felizes por ostentar felicidade, ainda que esta seja paradoxal: compartilhar sensações, revelar detalhes íntimos de suas vidas pessoais perfeitas, postar fotos e vídeos de bens, serviços e 
experiências, ou seja, de ostentar o consumo no intercâmbio de informações pessoais através das redes sociais.

E assim, “[...] a vida social já se transformou em vida eletrônica ou cibervida, e a maior parte dela se passa na companhia de um computador, um iPod ou um celular, e secundariamente ao lado de seres de carne e osso" (BAUMAN, 2008, p. 9).

Não estar inserido no contexto das redes sociais é equivalente à chamada "morte social" e os consumidores não tem sequer escolha: vivem uma vida eletronicamente medida, ditada e regulamentada pelas regras de consumo, que não oferece opção. "Aqueles que zelam por sua invisibilidade tendem a ser rejeitados ou considerados suspeitos de um crime. A nudez física, social e psíquica está na ordem do dia” (ENRIQUEZ, 2006, p. 49, tradução nossa).

Na sociedade de hiperconsumo o consumidor passou a centro da sociedade e a ditar as regras de consumo. Com isso, criou-se uma ilusão de que é ele o detentor de plena liberdade de escolha, quando na verdade, não se tem opção. O luxo passa a ser utilizado como forma de demarcar identidade, que confere um status social diferenciado, não tanto com a avidez de possuir, com relação ao acúmulo de riqueza no sentido material, mas pautado principalmente na esperança de se alcançar uma felicidade contraditória ou paradoxal.

As práticas cotidianas de consumo na hipermodernidade, atreladas ao fenômeno de influência das redes sociais atinge todos os setores da sociedade, pois interfere nas relações nas relações interpessoais, fortalece a exclusão e o individualismo, refletindo uma sociedade pulverizada de indivíduos solitários e famílias fragmentadas, o que atinge diretamente o processo de desenvolvimento social humano.

Diante disso, instala-se a necessidade de articular um novo debate em torno do processo de desenvolvimento, que analise caminhos mais concretos, onde a visão convencional deve ser superada e dar espaço a um novo debate que discuta a possibilidades de o capital social e a cultura contribuírem para o desenvolvimento social humano. Isso porque

Há múltiplos aspectos da cultura de cada povo que podem favorecer seu desenvolvimento econômico e social. É preciso descobri-los, potencializá-los e apoiar-se neles, e fazer isto com seriedade significa rever a agenda de desenvolvimento de um modo que resulte, posteriormente, mais eficaz, porque tomará em conta potencialidades da realidade que são da essência e que, até agora, foram geralmente ignoradas (IGLESIAS, 1997).

A realidade tem demonstrado o agravamento dos obstáculos na sociedade de hiperconsumo (individualismo, pobreza, carência de oportunidades econômicas, exclusão social, intolerância ou interferência excessiva de Estados repressivos), que precisam ser 


\section{A DEMOCRATIZAÇÃO DO LUXO E O CONSUMO DE SENSAÇÕES: PODER SIMBÓLICO E REDES SOCIAIS EM RELAÇÃO AO DESENVOLVIMENTO SOCIAL \\ HUMANO}

superados e removidos. Consumidores falhos são solitários e quando ficam sós por muito tempo tendem a se tornar arredios, não veem a sociedade como um grupo social, o que pode afetar todos os setores da sociedade.

Os fatores que alimentam a torrente consumista são a "[...] a desagregação dos lados sociais, o recuo dos sentimentos de inclusão numa comunidade, o aumento da incerteza, a fragilização da vida profissional e afetiva, o afrouxamento dos laços familiares [...] crises subjetivas e intersubjetivas" (LIPOVETSKY, 2008, p. 291). O que se pretende denunciar não é tanto o consumismo "[...] mas sua excrescência ou seu imperialismo constituindo um obstáculo ao desenvolvimento da diversidade das potencialidades humanas" (LIPOVETSKY, 2007, p. 370).

\footnotetext{
A sociedade de hiperconsumo pode ser resumida, sem risco de exageros, à experiência paradoxal da excrescência da mercantilização das necessidades e seu adimplemento em contraste com a privação de elementos básicos ao desenvolvimento humano. Democratizou-se o desejo, polinizado em toda a sociedade. Entretanto, o consumo de fato (meio para aplacar este desejo) ainda é um privilégio de poucos.

Pelos caminhos de pedra da hipermodernidade, trilham lado a lado pessoas, de mãos atadas em lugar de mãos dadas (FACHIN, 2015, p. 33).
}

Portanto, evidente que os padrões impostos pela sociedade de hiperconsumo são capazes de gerar um retrocesso desenvolvimento social humano, na medida em que impõem a prevalência do individualismo, exclusão social e desigualdade, considerados fatores relevante para a mobilização e crescimento social que visa uma sociedade equitativa. "A sociedade de consumidores tende a romper os grupos ou torna-los eminentemente fissíparos, favorecendo a pronta e rápida formação e a difusão dos enxames.” (BAUMAN, 2008, p. 101).

O processo de globalização trouxe sérias implicações na vida do ser humano e gerou uma aceleração muito grande das mudanças sociais. As grandes potências e empresas multinacionais cada dia ganham mais força e domínio sobre os países em desenvolvimento, o que contribui para o agravamento das desigualdades sociais.

Embora o globo não seja mais “[...] exclusivamente um conglomerado de nações, sociedades nacionais, Estados-nações, em suas relações de interdependência, dependência, colonialismo, imperialismo, bilateralismo, multilateralismo" (IANNI, 1999, p. 13), não se pode deixar de considerar que um mundo globalizado denota a ideia de dominação do mercado, onde o lucro ocupa o principal espaço na economia e se sobrepõe frente a dignidade humana, o que enfraquece a concepção de Estado-nação.

A globalização tem duas consequências importantes [...] em primeiro lugar, ela estende o modelo do Terceiro Mundo a países industrializados. No Terceiro Mundo, 
a sociedade divide-se em dois segmentos - um de extrema riqueza e privilégio, e outro de imensa miséria e desespero, formado por pessoas inúteis, dispensáveis (CHOMSKY, 1997, p. 13).

Com a forma de desenvolvimento priorizada no sistema capitalista, a sociedade pósmoderna passou a ser reconhecida como sociedade de consumo, onde "[...] o dilema sobre o qual mais se cogita hoje em dia é se é necessário consumir para viver ou se o homem vive para consumir" (BAUMAN, 1999). O consumo exposto não é apenas aquele decorrente da conduta natural do ser humano, sem limites temporais ou históricos, mas enquanto representação própria de reconhecimento simbólico do indivíduo na sociedade.

Segundo Bauman (1999, p. 101)

Da atividade do consumo não emergem vínculos duradouros. Os vínculos que conseguem se estabelecer no ato do consumo podem ou não sobreviver ao ato; podem manter os exames unidos pela duração do voo (ou seja até a próxima mudança de alvo), mas são reconhecidamente determinados pela ocasião, sendo frágeis e leves, com pouca influência, se é que possuem alguma, sobre os próximos movimentos das unidades ao mesmo tempo que iluminam muito pouco se é que chegam a iluminar as histórias passadas.

Para Carl Scmitt o traço definidor da soberania é a prerrogativa de eximir, excluir e colocar de lado uma categoria de pessoas às quais a lei é aplicada mediante a negação ou revogação de sua aplicação. O consumo como poder simbólico, tal como é posto hoje, com suas normas e exigências por vezes absurdas, pode ser considerado como um dos elementos que contribuem para o isolamento e um aparheid que não separa em razão da raça, mas pelo poder de compra.

O que se pretende denunciar neste estudo não é tanto o consumismo “[...] mas sua excrescência ou seu imperialismo constituindo um obstáculo ao desenvolvimento da diversidade das potencialidades humanas" (LIPOVETSKY, 2007, p. 370). Dada a complexidade da situação, existe uma preocupação em se analisar o consumismo enquanto obstáculo ao desenvolvimento social humano e traçar estratégias que possibilitem uma sociedade com mais equidade.

Como estratégias para os Estados superarem o simbólico e a felicidade paradoxal, visando a concretização do desenvolvimento social humano apresenta-se a investigação e aplicação de um "o processo de desenvolvimento numa abordagem ampla, integrando considerações econômicas, sociais e políticas" (SEN, 2000, p. 23) e a "expansão das liberdades reais que as pessoas desfrutam" (SEN, 2000, p. 17). 
O desenvolvimento social será realizado ou florescerá quando na sociedade exista o espaço para a promoção de condutas e/ou ações democráticas para a supressão das desigualdades ou a difusão de comportamento solidário em todos os setores sociais.

Diante do exposto é salutar abordar o tema "desenvolvimento" sob suas dimensões, que impliquem em novas políticas capazes de impulsionar o fortalecimento das sociedades democráticas para atingir o real desenvolvimento dos seus povos com dignidade e melhor qualidade de vida. A visão de desenvolvimento como sinônimo de crescimento econômico, e somente isto, necessita ser superada na perspectiva de assegurar um mundo melhor. (SARRETA, 2007, p.72)

A análise do desenvolvimento é muito mais ampla do que transparece. Os obstáculos gerados pela sociedade de hiperconsumo (individualismo, pobreza, carência de oportunidades econômicas, exclusão social, intolerância ou interferência excessiva de Estados repressivos, problemas econômicos e políticos), que precisam ser superados e removidos.

O desenvolvimento social é considerado como a consolidação de um processo de desenvolvimento baseado em outro tipo de crescimento e orientado por outra visão sobre o que seja a boa sociedade. Possui como finalidade a construção de uma civilização com equidade na distribuição da renda para melhorar os direitos de grandes massas, em que seja mais importante o ser do que o ter.

Esta revalorização de valores será para a reconciliação de os seres humanos entre si. O desenvolvimento abarca é esta relacionado com os direitos humanos, com a possibilidade de os cidadãos exercerem seus direitos políticos, cívicos, econômicos, sociais e culturais, enfim, direitos coletivos, como o direito ao meio ambiente sadio, direitos do consumidor, ao desenvolvimento, a uma vida digna (SARRETA, 2007, p.119).

O grande desafio social contemporâneo é conjugar solidariedade, liberdade e alteridade, sem perder de vista a noção de dignidade para a busca da felicidade, possuindo como base a igualdade, ou seja, a suplantação da inclusão pelo simbólico consumista de uma minoria que cria padrões.

\section{CONCLUSÃo}

A realidade tem demonstrado que a análise do desenvolvimento é muito mais ampla do que transparece. Isso fica ainda mais claro diante do agravamento dos obstáculos na sociedade de hiperconsumo (individualismo, pobreza, carência de oportunidades econômicas, Revista de Direito e Sustentabilidade | e-ISSN: 2525-9687 | Salvador | v. 4 | n. 1 | p. 77 - 94 | Jan/Jun. 2018 
exclusão social, intolerância ou interferência excessiva de Estados repressivos), que precisam ser superados e removidos.

A ascensão da economia ocorrida, sobretudo após os anos 2000 contribuiu para a "democratização do luxo" que está basicamente consubstanciada no "consumo das sensações", onde o supérfluo ganha posição de destaque, o que influencia diretamente em todos os setores da sociedade e também interfere no indivíduo. Buscou-se demonstrar a evolução do consumo, partindo da aquisição de objetos como elemento de distinção social e símbolo de pertencimento a grupos sociais, até a aquisição como espécie de satisfação pessoal e merecimento e como o simbólico se desenvolve nessa esfera.

O que se pretende denunciar não é tanto o consumismo, mas as consequências de seu imperialismo enquanto obstáculo ao desenvolvimento da diversidade das potencialidades sociais e humanas. Dada a complexidade da situação, existe uma preocupação em se analisar o consumismo enquanto obstáculo ao desenvolvimento social humano e traçar estratégias que possibilitem uma sociedade com mais equidade.

As sensações e experiências geradas pelo uso de produtos ou serviços de luxo ou, melhor dizendo, aquelas supostamente imaginadas, passam a ser ditadas por hábitos idealmente adquiridos e por uma cultura que envolve sobretudo o esquecimento, não o aprendizado.

O que realmente conta é a volatilidade, a instigante experiência em viver aquilo que não sabia que existia, de ser atormentado pelos desejos ainda não percebidos e nem suspeitados. Na sociedade de hiperconsumo os fatores que alimentam a torrente consumista são a desagregação dos laços sociais, o recuo dos sentimentos de inclusão numa comunidade, o aumento da incerteza, a fragilização da vida profissional e afetiva, o afrouxamento dos laços familiares.

A identificação do significado de luxo, baseado no consumo e nas experiências, relacionada à conjectura atual de exposição através das redes sociais, permite concluir que os padrões impostos pela atual sociedade de hiperconsumo, sobretudo com a ascensão das redes sociais, são capazes de gerar um retrocesso no desenvolvimento social.

Assim, cabe aos Estados, adotarem estratégias para superar o simbólico com relação ao consumo, em busca da concretização do desenvolvimento social humano. O grande desafio social contemporâneo é conjugar solidariedade, liberdade e alteridade, sem perder de vista a noção de dignidade para a busca da felicidade, possuindo como base a igualdade, ou seja, a suplantação da inclusão pelo simbólico consumista de uma minoria que cria padrões. 


\section{A DEMOCRATIZAÇÃO DO LUXO E O CONSUMO DE SENSAÇÕES: PODER SIMBÓLICO E REDES SOCIAIS EM RELAÇÃO AO DESENVOLVIMENTO SOCIAL \\ HUMANO}

\section{REFERÊNCIAS}

BAUMAN, Zygmunt. Globalização: as consequências humanas. Tradução Marcus Penchel. Rio de Janeiro: Zahar, 1999.

, Zygmunt. Vida para consumo: a transformação das pessoas em mercadoria. Tradução Carlos Alberto Medeiros. Rio de Janeiro: Zahar, 2008.

BOURDIEU, Pierre. O poder simbólico. Rio de Janeiro: Bertrand Brasil, 2000.

CHOMSKY, N. A minoria próspera e a multidão inquieta. 2. ed. Rio de Janeiro: UnB, 1997.

FACHIN, Luiz Edson. Reflexões sobre risco e hiperconsumo. In: OLIVEIRA, Andressa Jarletti Gonçalves de; XAVIER, Luciana Pedroso (Orgs.). Repensando o direito do consumidor III: 25 anos de CDC: conquistas e desafios. v. 19. col. Comissões. Curitiba: OABPR, 2015.

GIDDENS, Antony. Sociologia. Tradução Ronaldo Cataldo Costa. 6. ed. Porto Alegre: Penso, 2012.

IANNI, O. Teorias da globalização. 5. ed. Rio de Janeiro: Civilização Brasileira, 1999.

IGLESIAS, Enrique. Cultura, educación y desarollo. Assembléia Geral da Unesco. Paris: 1997.

JODELET, Denise. La representación social: fenómenos, concepto y teoria. In:

MOSCOVICI, Serge (Org). Pensamiento y vida social. Barcelona/Buenos Aires/México: Paidós, Psicologia Social, 2, 1985.

LIPOVETSKY, Gilles. A felicidade paradoxal: ensaio sobre a sociedade de hiperconsumo. Tradução Maria Lucia Machado. São Paulo: Companhia das Letras, 2007.

Gilles; ROUX, Elyette. O luxo eterno: da idade do sagrado ao temoi das marcas.

Tradução Maria Lúcia Machado. São Paulo: Companhia das Letras, 2005.

MCLEÓDE. “A formação do Simbólico”. Traduzido do original francês por Maria Nazaré Machado Mcleod - Universidade Estadual Feira de Santana - Paru dans Canadart V. Revista do Núcleo de Estudos Canadenses, Universidade do Estado da Bahia. Associação Brasileira de Estudos Canadenses - ABECAN. Salvador, Bahia, 1997, 147-162.

MOSCOVICI, Serge. A Representação Social da Psicanálise. Rio de Janeiro: Zahar, 1978.

PUTNAM, Robert. Comunidade e democracia. A experiência da Itália moderna. Rio de Janeiro: Fundação Getúlio Vargas, 1996. Tradução de Making Democracy Work: Civic Traditions in Modern Italy (1993).

SARRETA, Cátia Rejane Lickzbinski. Meio ambiente e consumo sustentável: direitos e deveres do consumidor. Passo Fundo: Ed. Universidade de Passo Fundo, 2007. 
SEN, Amarya Kumar. Desenvolvimento como liberdade. Tradução Laura Teixeira Motta. São Paulo: Companhia das Letras, 2000.

TOURAINE, Alain. O que é democracia? Petrópolis: Vozes, 1994. 